\title{
Peripheral Arterial Insufficiency: A Study of Prevalence and Factors Associated with Complications in Baja California Sur
}

\begin{abstract}
Del Rio-Sanchez G ${ }^{1}$, Ponce de Leon-Garcia $\mathrm{O}^{2}$, Velazquez-Figueroa $\mathrm{MA}^{3}$, Ochoa $\mathrm{MC}^{4}$ and Ramirez-Leyva DH ${ }^{5 *}$

${ }^{1}$ Department of Family Medicine, General Hospital Zone \#1 (IMSS), Baja California Delegation, Mexico ${ }^{2}$ Department of Angiology, General Hospital Zone \#1 (IMSS), Baja California Delegation, Mexico ${ }^{3}$ Department of Emergency, General Hospital Zone \#1 (IMSS), Baja California Delegation, Mexico ${ }^{4}$ Department of Pediatrics, Regional General Hospital \#1 (IMSS), Sonora Delegation, Sonora, Mexico ${ }^{5}$ Department of Family Medicine, Family Medicine Unit \#1 (IMSS), Sonora Delegation, Sonora, Mexico

*Correspondling author: Ramirez Leyva Diego Hazael, Department of Family Medicine, Regional General Hospital \#1 (IMSS), Sonora Delegation, Sonora, México, Colonia Centro, Cd. Obregon, Sonora, Mexico
\end{abstract}

Received: February 15, 2017; Accepted: March 06, 2017; Published: March 13, 2017

\begin{abstract}
Background: Changes in the hygienic and dietary habits of population have favored an increase in peripheral arterial disease (PAI). It has a global prevalence between $3-10 \%$; although, this number has increased to $15-20 \%$ in the last years. PAI is a disease characterized by stenosis of arterial lumen causing haemodynamic changes at arterial blood flow level with reduction in perfusion pressure and tissue damage.
\end{abstract}

Aim: So the purpose of this study is to determinate prevalence and factors associated to complications in patients with peripheral arterial insufficiency in Baja California Sur, Mexico.

Design and Setting: Comparative cross-sectional study.

Methods: In 156 patients with peripheral arterial insufficiencyduring 20152016 in General Hospital Zone \#1, La Paz, Baja California, Mexico; prevalence of PAI was calculated. There were two groups (with sequels/without sequels) based on presence of sequels of PAl; it was used $80 \%$ statistical power and $95 \%$ interval confidence; association was established by calculating odds ratios, chi-squared and Student T test for statistical significance $(p<0.05)$.

Results: $61 \%$ were men, mean age 65.6 years $( \pm 13.3)$. The association between PAI sequels and comorbidities reported the following results: age [p 0.32], gender (man) [p 0.23], Chronic Renal Failure (with CRF) [p 0.05], Diabetes Mellitus (with DM) [p 0.42], Arterial Hypertension (With AH) [p 1.0], Dyslipidemia (with $\mathrm{DL}$ ) [p 0.49] and Smoking (With SM) [p 0.45]. When comparing PAI sequels with type of treatment, we found the following: treatment (conventional surgical) [p 1.0], treatment (bypass) [p 0.3] and treatment (angioplasty) [p 1.0]. PAI prevalence was $6.2 \%$.

Conclusion: Prevalence of PAI founded is similar to reported in national information; however the prevalence of complication or sequels is higher than reported in other cities of Mexico.

Keywords: Peripheral Arterial Insufficient; Prevalence; Angiology

\section{Introduction}

In recent years amputations have increased in Mexico and in the world secondary to advanced occlusive vascular disease. Approximately $10 \%$ of Mexican population has Diabetes Mellitus (DM), an important risk factor for the development of peripheral arterial insufficiency [1]. Occlusive peripheral arterial disease occurs in 3 to $10 \%$ of the world's population, although this disease increases considerably in people over 70 years (15\% to 20\%) [2]. Risk factors such as smoking, type 2 diabetes mellitus and dyslipidemia should be strictly controlled to delay atherosclerotic process in peripheral vessels [2]. Related symptoms may range from pain on walking to presence of a chronic ulcer that does not heal properly [1].

Symptoms may occur in 3 forms: intermittent claudication, critical ischemia and acute arterial insufficiency; intermittent claudication and presence of critical ischemia are associated with vascular events such as myocardial infarction or cerebral infarcts. It has been reported that $25 \%$ of patients with critical ischemia have died within first year since the event and another 25\% have suffered a major amputation. Only $25 \%$ of these patients have a successful surgical procedure [1-2]. In the United States, it is estimated that frequency of amputation is from 1 to $7 \%$ at 5-10 years. Smoking, an ankle-arm index less than 0.6 and presence of type 2 diabetes mellitus are considered factors of poor prognosis [3].

The costs of PAI are very high, especially in quality of life and environment; the real area of

train primary care physicians tospeinfigsmedrbodeperetionsofehciardisiate [4-5]. The diagnostic methods in PAI are clinical history, physical examination and non-invasive tests. Therapeutic options available for treatment of chronic ischemia are very broad [5]. Currently, its management can be divided into preventive, pharmacological and surgical (conventional surgery or endovascular treatment). It is essential that a vascular surgeon be in charge of treatment of this
J Fam Med - Volume 4 Issue 3 - 2017

ISSN : 2380-0658 | www.austinpublishing group.com

Ramirez-Leyva et al. (C) All rights are reserved
Citation: Del Rio-Sanchez G, Ponce de Leon-Garcia O, Velazquez-Figueroa MA, Ochoa MC and Ramirez-Leyva DH. Peripheral Arterial Insufficiency: A Study of Prevalence and Factors Associated with Complications in Baja California Sur. J Fam Med. 2017; 4(3): 1113 


\begin{tabular}{|c|c|c|c|c|}
\hline & & $\begin{array}{c}\text { With } \\
\text { Sequels }\end{array}$ & $\begin{array}{l}\text { Without } \\
\text { Sequels }\end{array}$ & \\
\hline Variable & Subtype & $\mathbf{N}$ & $\mathbf{N}$ & $\mathbf{p}$ \\
\hline \multirow{2}{*}{ Gender } & Man & 47 & 47 & \multirow[b]{2}{*}{0.23} \\
\hline & Woman & 25 & 35 & \\
\hline \multirow{2}{*}{ Smoking } & With Smoking & 53 & 19 & \multirow[b]{2}{*}{0.45} \\
\hline & Without Smoking & 60 & 24 & \\
\hline \multirow{2}{*}{$\begin{array}{l}\text { Chronic Renal } \\
\text { Failure }\end{array}$} & With CRF & 41 & 36 & \multirow[b]{2}{*}{0.05} \\
\hline & Without CRF & 31 & 48 & \\
\hline \multirow[b]{2}{*}{ Diabetes Mellitus } & With DM & 43 & 52 & \multirow[b]{2}{*}{0.42} \\
\hline & Without DM & 29 & 32 & \\
\hline \multirow{2}{*}{$\begin{array}{c}\text { Arterial } \\
\text { Hypertension }\end{array}$} & With $\mathrm{AH}$ & 46 & 46 & \multirow[b]{2}{*}{1.0} \\
\hline & Without $\mathrm{AH}$ & 26 & 38 & \\
\hline \multirow[b]{2}{*}{ Dyslipidemia } & With dyslipidemia & 35 & 42 & \multirow[b]{2}{*}{0.49} \\
\hline & $\begin{array}{c}\text { Without } \\
\text { dyslipidemia }\end{array}$ & 37 & 42 & \\
\hline
\end{tabular}

N: Frequency; p: Chi Square.

type of patients and offers the best alternative [1]. Indication of surgical treatment (conventional or endovascular) will depend on joint assessment of two fundamental aspects, clinical situation of patient and vascular territory that needs reconstruction. The clearest indication for revascularization is a patient with advanced stages of ischemia and a high risk of limb loss [6].

Ankle-arm index (AAI) and finger-arm index (FAI) allow diagnosis of this disease, being used as cardiovascular risk markers. Oscillometry, segmental pressures and spectral analysis of doppler curves are mainly used to know location of disease; all these are hemodynamic explorations. Morphological, echo-doppler (also contributes hemodynamic information), computed tomography, magnetic angioresonance and arteriography, give more precise information on location and characteristics of the lesions [7]. Based on the above, main objective of this study was to determinate prevalence and factors associated to complications in patients with peripheral arterial insufficiency in Baja California Sur, Mexico.

\section{Materials and Methods}

A comparative, cross-sectional study was carried out in the General Hospital Zone \# 1 of the Mexican Institute of Social Security (IMSS) in La Paz, Baja California Sur, Mexico, from March 2015 to March 2016. All medical records of patients in angiology department were reviewed and information was collected of patients that met the following inclusion criteria: any gender, older than 18 years and diagnosis of PAI and were eliminated those who did not have complete information. The following data were obtained directly from the medical records: age, gender, diagnosis of PAI, type of treatment, complications of PAI, squeals of PAI and comorbidities or chronic degenerative diseases as Diabetes Mellitus (DM), Chronic Renal Failure (CRF) and arterial hypertension (HA).

The data obtained was integrated into data collection sheets and analyzed using the SPSS program version 20 in Spanish, where we applied descriptive statistics; for qualitative variables frequencies and percentages were used and for quantitative variables mean and standard deviation were used. For bivariate analysis was considered
Table 2: Association between PAI sequels and type of treatment.

\begin{tabular}{|c|c|c|c|c|}
\hline & & $\begin{array}{c}\text { With } \\
\text { Sequels }\end{array}$ & $\begin{array}{l}\text { Without } \\
\text { Sequels }\end{array}$ & \\
\hline Variable & Subtype & $\mathbf{N}$ & $\mathbf{N}$ & $\mathbf{p}$ \\
\hline \multirow{2}{*}{ Conventional surgical } & With CS & 1 & 3 & \multirow[b]{2}{*}{0.80} \\
\hline & Without CS & 39 & 81 & \\
\hline \multirow{2}{*}{ Bypass } & With Bypass & 17 & 16 & \multirow[b]{2}{*}{0.30} \\
\hline & Without Bypass & 55 & 68 & \\
\hline \multirow{2}{*}{ Angioplasty } & With Angioplasty & 34 & 1 & \multirow[b]{2}{*}{1.0} \\
\hline & Without Angioplasty & 38 & 83 & \\
\hline
\end{tabular}

$\mathrm{N}$ : Frequency; \%: Percentage; p: Chi Square.

statistically significant a $\mathrm{p}<0.05$, with a $95 \%$ confidence interval, all variables were dichotomized to apply odds ratio and chi square, for quantitative variables student $\mathrm{T}$ was used. The Protocol was authorized by the Local Committee of Research and Ethics in Health Research from the General Hospital Zone\#1, where the study took place.

\section{Results}

Productivity records of angiology department in General Hospital Zone \# 1 of La Paz, Baja California Sur, Mexico, were reviewed, finding 2108 patients between March 2015 to March 2016 of which 156 patients had diagnosis of peripheral arterial insufficiency, estimating a prevalence of $6.26 \%$; mostly men with $61.0 \%$ compared to $39.0 \%$ women; mean age was $65.6( \pm 13.3)$ years. In medical records $72.4 \%$ had at least one comorbidity: Smoking (72.4\%), Diabetes Mellitus (60.9\%), Arterial Hypertension (59\%), Dyslipidemia (49.9\%) and Chronic Renal Failure (50\%). In type of treatment $22.4 \%$ of patients had conventional surgical, $21.2 \%$ arterial Bypass and $2 \%$ angioplasty. In sequels of PAI, $46.2 \%$ had at least one, $23.7 \%$ chronic ulcers and $21.2 \%$ amputation.

The following results were obtained for the association of PAI sequels and comorbidities (Table 1): age [p 0.32], gender (man) [p 0.23], Chronic Renal Failure (with CRF) [p 0.05], Diabetes Mellitus (with DM) [p 0.42], Arterial Hypertension (With AH) [p 1.0], Dyslipidemia (with DL) [p 0.49] and Smoking (With SM) [p 0.45]. When comparing PAI sequels with type of treatment, we found the following (Table 2): treatment (conventional surgical) [p 1.0], treatment (bypass) [p 0.3] and treatment (angioplasty) [p 1.0].

\section{Discussion}

In research study we found in angiology department a total of 2108 consultations during the months of March 2015 to March 2016. With data obtained, prevalence of peripheral arterial insufficiency was $6.26 \%$ which is similar to reported by Alzamora et al in Spain (2010) with a prevalence of 7.6\% [8] and Aguilar et al (2007) who report a prevalence of 3 to $10 \%$ in Mexico [2]. Our research agrees with Gutiérrez et al (2014) in factors associated with presence of PAI (smoking and dyslipidemia) [1].

Presence of complications was $23.7 \%$ of cases, which is different to reported by Secretary of Health in Mexico (2009), where was reported a frequency of 1-7\%. Based on above, in Baja California Sur presence of complications is very high and this research can be basis for future studies. According to Ohare et al, arterial insufficiency is 
very frequent in patients with renal insufficiency and there is a strong association with the wrist-ankle index so it is considered important to detect asymptomatic patients [9] which is similar to that found in our study where there was an association between presence of complications due to arterial insufficiency and chronic renal failure (p 0.05).

\section{Conclusion}

In this research it is concluded that during March 2015 to March 2016 a total of 156 patients with a diagnosis of peripheral arterial insufficiency were found, with a frequency similar to reported in international literature. A total of 33 patients with amputation secondary to PAI were found with a prevalence of $21.2 \%$, which is alarmingly high and different from what was reported at national level in Mexico; the development of other lines of investigation that allow us to know risk factors that influence for presenting complications in patients with PAI must be implemented.

\section{References}

1. Gutiérrez C, Sánchez C, Lizola M, Singler L, Mendieta H. Arterial insufficiency of the extremities. Angiologia. 2014; 42: 170-179.

2. Aguilar R, Marquina R. Current status of occlusive peripheral arterial disease (OPAD). Acta médica grupo ángeles. 2007; 4: 187-196.
3. Diagnosis and treatment of peripheral arterial disease. México: Secretary of Health; 2009

4. Arterial disease of the lower extremities as a problem. Prevalence, risk factors or risk groups (elderly, smokers, diabetics), economic and social impact. Avances Cardiol. 2014; 34: S11-S16.

5. Baena Diez J, García V, Tomas J, Martínez M, Martin P, González T, Pomares $\mathrm{M}$, et al. Epidemiology of cardiovascular diseases and risk factors in primary care. Rev Esp Cardiol. 2005; 58: 367-373.

6. Serrano F, Martin C. Peripheral arterial disease: pathophysiological, clinical and therapeutic aspects. Rev Esp Cardiol. 2007; 60: 969-982.

7. Blanes-Mompo JI, Plaza-Martinez A, Torres-Blanco A, Zaragoza-Garcia J, Martínez-Parreno C, Al-Raies-Bolanos B, et al. Diagnosis of occlusive arteria disease of the lower limbs. Anales de Cirugia Vascular. 2009; 23: 12-18.

8. Alzamora MA, Fores R, Baena-Diez JM, Pera G, Toran P, Sorribes M, et al. The Peripheral Arterial disease study (PERART/ ARTPER): prevalence and risk factors in the general population. BMC. 2010; 10: 2-11.

9. Ohare A, Glodden D, Fox C, Chi-yuan H. High Prevalence of Peripheral Arterial Disease in Persons With Renal Insufficiency Results From the National Health and Nutrition Examination Survey 1999-2000. PAD and Renal Insufficiency. 2003; 23: 321-523.
J Fam Med - Volume 4 Issue 3 - 2017

ISSN : 2380-0658 | www.austinpublishinggroup.com

Ramirez-Leyva et al. (C) All rights are reserved
Citation: Del Rio-Sanchez G, Ponce de Leon-Garcia O, Velazquez-Figueroa MA, Ochoa MC and Ramirez-Leyva DH. Peripheral Arterial Insufficiency: A Study of Prevalence and Factors Associated with Complications in Baja California Sur. J Fam Med. 2017; 4(3): 1113. 